\title{
ANALISIS FAKTOR - FAKTOR YANG MEMPENGARUHI KEIKUTSERTAANSENAM HAMIL PADA IBU HAMIL TRIMESTER III DI BPM HJ. DINCE SAFRINA SST
}

\author{
Wiwi Sartika ${ }^{1}$ Siti Qomariah ${ }^{2}$ \\ Program Studi D III Kebidanan Universitas Abdurrab \\ Jl.Riau Ujung No.73, Pekanbaru 28292 Indonesia \\ wiwi.sartika@univrab.ac.id, siti.qomariah@univrab.ac.id
}

\begin{abstract}
Pregnancy and childbirth are natural processes for a woman, during pregnancy the body will experience many adaptations of physiology and psychology. Physiological adaptation consists of changes in the reproductive system, changes in the cardiovascular system, changes in the respiratory system, changes in the gastrointestinal system, changes in the renal system, changes in the endocrine system, changes in the abdominal wall and skin, and metabolic changes while psychological changes consist of stressors during pregnancy and changes in pregnancy. The purpose of this study is to determine the analysis of factors that influence the participation of pregnancy exercise in trimester III pregnant women at the BPM $\mathrm{Hj}$. Dince Safrina, SST. The research used was quantitative observational analytic (cross-sectional) with elements of independent and dependent variables. The population in this study were all mothers - third trimester pregnant women (gestational age above 28 weeks) who visited the BPM Hj. Dince Safrina, SST. Samples with a sample of 61 respondents. Sampling is done in Accidental Sampling. Data used are primary data by distributing questionnaires. Data analysis was done by univariate, bivariate with chi-square test and multivariate with multiple logistic regression tests. The results of the multivariate analysis variables that most influenced the participation of pregnant gymnastics were the motivation variable (OR: 6.93; 95\% CI: 1.95-24.60). The conclusion in this study is that high motivation from both pregnant women and families 6.93 times affected pregnant women to take part in pregnancy exercises at the nearest health facility.
\end{abstract}

Keywords: Pregnant Women, Participation, Pregnant Gymnastics

\begin{abstract}
ABSTRAK
Kehamilan dan persalinan merupakan proses yang alamiah bagi seorang wanita, pada masa kehamilan tubuh akan banyak mengalami adaptasi fisiologi dan psikologi. Adaptasi fisiologi terdiri dari perubahan sistem reproduksi, perubahan sistem kardiovaskuler, perubahan sistem pernapasan, perubahan sistem gastrointestinal, perubahan sistem renal, perubahan sistem endokrin, perubahan dinding perut dan kulit, serta perubahan metabolik sedangkan perubahan psikologi terdiri dari stressor pada saat kehamilan dan perubahan psikologi kehamilan. Tujuan penelitian ini Untuk mengetahui Analisis faktor - Faktor Yang Mempengaruhi Keikutsertaan senam Hamil Pada Ibu Hamil Trimester III Di BPM Hj. Dince Safrina, SST. Penelitian yang digunakan bersifat kuantitatif analitik observasional (cross-sectional) dengan unsur variabel independen dan dependen. Populasi dalam penelitian ini adalah seluruh ibu ibu hamil trimester III (usia kehamilan diatas 28 minggu) yang berkunjung di BPM $\mathrm{Hj}$. Dince Safrina, SST. Sampel dengan jumlah sampel 61 responden. Pengambilan sampel dilakukan secara Accidental Sampling.. Data yang digunakan adalah data primer dengan menyebarkan kuesioner. Analisis data dilakukan secara univariat, bivariat dengan uji chisquare dan multivariat dengan uji regresi logistik ganda. Hasil analisis multivariat variabel yang paling mempengaruhi keikutsertaan senam hamil adalah variabel motivasi (OR:6,93;
\end{abstract}


95\%CI: 1,95-24,60). Kesimpulan dalam penelitian ini adalah motivasi yang tinggi baik dari diri ibu hamil maupun dari keluarga 6,93 kali mempengaruhi ibu hamil untuk mengikuti senam hamil di fasilitas kesehatan terdekat.

Kata Kunci : Ibu Hamil, Keikutsertaan, Senam Hamil

\section{Pendahuluan}

Kehamilan dan persalinan merupakan proses yang alamiah bagi seorang wanita, pada masa kehamilan tubuh akan banyak mengalami adaptasi fisiologi dan psikologi. Adaptasi fisiologi terdiri dari perubahan sistem reproduksi, perubahan sistem kardiovaskuler, perubahan sistem pernapasan, perubahan sistem gastrointestinal, perubahan sistem renal, perubahan sistem endokrin, perubahan dinding perut dan kulit, serta perubahan metabolik sedangkan perubahan psikologi terdiri dari stressor pada saat kehamilan dan perubahan psikologi kehamilan [1]

Setiap ibu hamil seharusnya mendapat perawatan kehamilanya secara baik, dengan cara memeriksakan kehamilanya, tetapi pada kenyataanya masih banyak ibu hamil belum mengerti yang lebih dalam tentang pemeriksaan kehamilan (ANC). Menurut data rekam medis yang menurut Depkes RI (2012), kondisi derajat kesehatan di Indonesia ini masih memprihatinkan antara lain ditandai dengan tingginya AKI (Angka Kematian Ibu) yaitu 146/100.000 kelahiran hidup dan mati bayi baru lahir 78,01/1000 (SDKI 2012/2013). Beberapa faktor yang melatarbelakangi resiko kematian adalah kurangnya partisipasi ibu yang disebabkan tingkat pendidikan ibu rendah, kemampuan ekonomi keluarga rendah, kedudukan social budaya yang tidak mendukung [2]

Pada trimester ketiga (27-40 minggu), kecemasan menjelang persalinan ibu hamil pertama akan muncul. Untuk memutus siklus kecemasan tersebut, maka senam hamil sebagai salah satu pelayanan prenatal, merupakan suatu alternatif pada ibu hamil karena dalam gerakan senam hamil terkandung efek relaksasi yang dapat menstabilkan emosi ibu hamil serta senam hamil dapat memperkuat otot-otot.Senam hamil adalah kegiatan olah raga yang dilakukan dengan tujuan membuat elastis otot dan ligamen yang ada di panggul, memperbaiki sikap tubuh, mengatur kontraksi dan relaksasi, serta mengatur teknik pernafasan, sehingga mempermudah dalam proses persalinan khususnya persalinan normal [4]

Keikutsertaan ibu hamil dalam melakukan senam hamil menyangkut perilaku kesehatan ibu hamil. Menurut L. Green (Notoatmodjo, 2003), perilaku kesehatan seseorang atau masyarakat dipengaruhi oleh 2 faktor pokok, yakni faktor perilaku (behavior causes) dan faktor di luar perilaku (nonbehavior causes). Perilaku itu sendiri ditentukan atau terbentuk dari 3 faktor, yaitu: faktor predisposisi (predisposing factor), yang terwujud dalam pengetahuan, sikap, tradisi, kepercayaan, keyakinan, nilai-nilai, pendidikan, dan sebagainya. Faktor pendukung (enabling factors), yang terwujud dalam lingkungan fisik, tersedia atau tidak tersedianya fasilitas-fasilitas atau, sarana-sarana kesehatan, misalnya puskesmas, obatobatan, alat-alat kontrasepsi, jamban, dan sebagainya [5]

Faktor pendorong (reinforcing factor) yang terwujud dalam sikap dan perilaku tokoh masyarakat, tokoh agama, petugas kesehatan, atau petugas yang lain, yang merupakan 
kelompok referensi dari perilaku masyarakat. Faktor yang bersumber dari dalam individu yang dapat mempengaruhi keikutsertaan ibu hamil dalam melakukan senam hamil adalah pendidikan dan pekerjaan. Pendidikan dan pekerjaan juga erat kaitanya dengan pengetahuan ibu hamil. Ibu hamil yang bekerja membantu suami mencukupi nafkah keluarga tidak memiliki banyak waktu untuk mengikuti kegiatan senam hamil. Sedangkan ibu hamil yang tidak bekerja lebih dapat meluangkan waktunya untuk mengikuti senam hamil. [6]

Rumusan masalah dalam penelitian ini adalah bagaimana Analisis faktor - Faktor Yang Mempengaruhi Keikutsertaan senam Hamil Pada Ibu Hamil Trimester III Di BPM Hj. Dince Safrina, SST

Tujuan penelitian ini Untuk mengetahui Analisis faktor - Faktor Yang Mempengaruhi Keikutsertaan senam Hamil Pada Ibu Hamil Trimester III Di BPM Hj. Dince Safrina, SST.

Hasil Penelitian ini diharapkan berguna bagi ibu-ibu hamil trimester III agar bisa mengikuti senam hamil yang bertujuan nantinya bisa membantu memperlancar proses persalinan.

\section{METODE}

Penelitian yang digunakan bersifat kuantitatif analitik observasional (cross-sectional) dengan unsur variabel independen dan dependen. Populasi dalam penelitian ini adalah seluruh ibu - ibu hamil trimester III (usia kehamilan diatas 28 minggu) yang berkunjung di BPM Hj. Dince Safrina, SST. Sampel dengan jumlah sampel 61 responden. Pengambilan sampel dilakukan secara Accidental Sampling. Data yang digunakan adalah data primer dengan menyebarkan kuesioner. Analisis data dilakukan secara univariat, bivariat dengan uji chi-square. Hasil analisis Bivariat variabel Dari hasil seleksi bivariat yang telah dilakukan didapatkan hasil semua variabel mempunyainilai $p<0,25$. Sehingga semua variabel independen dimasukkan ke dalammodel multivariat. Pengolahan data dilakuakn dengan tahap editing, coding, proseding, cleaning dan tabulating. Analisis data dilakukan secara univariat,bivariat dan multivariat.

\section{HASIL DAN PEMBAHASAN}

a. Analisis Univariat

Distribusi Frekuensi Analisis Univariat Karakteristik Responden

\begin{tabular}{|c|c|c|}
\hline Variabel & Frekuensi & $\%$ \\
\hline \multicolumn{3}{|l|}{ Umur } \\
\hline Resiko Tinggi & 28 & 45.9 \\
\hline Resiko Rendah & 33 & 54.1 \\
\hline \multicolumn{3}{|l|}{ Pendidikan } \\
\hline Tinggi & 40 & 65.6 \\
\hline Rendah & 21 & 34.4 \\
\hline \multicolumn{3}{|l|}{ Paritas } \\
\hline Nullipara & 33 & 54.1 \\
\hline Primipara & 28 & 45.9 \\
\hline \multicolumn{3}{|l|}{ Pengetahuan } \\
\hline Baik & 39 & 63.9 \\
\hline Kurang & 22 & 36.1 \\
\hline \multicolumn{3}{|l|}{ Pekerjaan } \\
\hline Bekerja & 23 & 37.7 \\
\hline TidakBekerja & 38 & 62.3 \\
\hline \multicolumn{3}{|l|}{ Motivasi } \\
\hline Tinggi & 41 & 67.2 \\
\hline Rendah & 20 & 32.8 \\
\hline
\end{tabular}

diketahui bahwa Mayoritas Responden Berumur 33 dengan54,1\%. Mayoritas responden berpendidikan tinggi dengan jumlah 40 dengan65,6\%.Mayoritas responden nullipara dengan jumlah 33 dengan 54,1 \%.Mayoritas responden berpengetahuan baik dengan jumlah 39 dengan 63,9\%.Mayoritas responden tidak bekerja dengan jumlah 38 dengan $62,3 \%$.Mayoritas responden memiliki motivasi tinggi dengan jumlah 41 dengan 657,2\%.Mayoritas respondenyang tidak mengikuti senam 
hamil dengan jumlah 31 dengan 50,8 $\%$.

b. Analisi Bivariat

Hubungan Beberapa Variabel
Independen Dengan Faktor
YangMempengaruhi Keikutsertaan
Senam hamil Pada Ibu Hamil
Trimester III di BPM Hj. Dince
Safrina, SST

Safrina, SST

\begin{tabular}{|c|c|c|c|c|c|c|c|c|}
\hline \multirow{2}{*}{$\begin{array}{c}\text { Variabel } \\
\text { Indepen } \\
\text { den }\end{array}$} & & Sena & Hamil & & Jmh & \multirow[b]{2}{*}{$\%$} & \multirow{2}{*}{$\begin{array}{c}P \\
\text { Val } \\
\text { ue }\end{array}$} & \multirow{2}{*}{$\begin{array}{c}\text { OR } \\
(95 \\
\% \\
\text { CI })\end{array}$} \\
\hline & $\begin{array}{c}\text { Ikut } \\
\text { n }\end{array}$ & $\%$ & $\begin{array}{c}\text { Tidak } \\
\text { n }\end{array}$ & $\begin{array}{c}\text { Ikut } \\
\%\end{array}$ & $\mathrm{n}$ & & & \\
\hline $\begin{array}{l}\text { Umur } \\
\text { Resiko } \\
\text { Tinggi }\end{array}$ & 15 & $\begin{array}{c}53.6 \\
\%\end{array}$ & 15 & $46.4 \%$ & 28 & 100 & $\begin{array}{l}0,5 \\
27\end{array}$ & $\begin{array}{c}1,38 \\
5\end{array}$ \\
\hline $\begin{array}{l}\text { Resiko } \\
\text { Rendah }\end{array}$ & 15 & $\begin{array}{c}45.5 \\
\% \\
\end{array}$ & 18 & $54.5 \%$ & 33 & 100 & & \\
\hline $\begin{array}{l}\text { Pendidi } \\
\text { kan } \\
\text { Tinggi }\end{array}$ & 24 & 60.0 & 16 & $40.0 \%$ & 40 & 100 & $\begin{array}{c}.01 \\
8\end{array}$ & $\begin{array}{c}3,75 \\
0\end{array}$ \\
\hline Rendah & 6 & $\begin{array}{c}\% \\
28.6 \\
\%\end{array}$ & 15 & $71.4 \%$ & 21 & 100 & & \\
\hline $\begin{array}{l}\text { Paritas } \\
\text { Nulli } \\
\text { Para }\end{array}$ & 20 & 60.6 & 13 & $39.4 \%$ & 33 & 100 & $\begin{array}{c}.05 \\
1\end{array}$ & $\begin{array}{c}2,76 \\
9\end{array}$ \\
\hline $\begin{array}{l}\text { Primi } \\
\text { Para }\end{array}$ & 10 & $\begin{array}{c}\% \\
35.7 \\
\%\end{array}$ & 18 & $64.3 \%$ & 28 & 100 & & \\
\hline $\begin{array}{l}\text { Pengeta } \\
\text { huan } \\
\text { Baik }\end{array}$ & 23 & 59.0 & 16 & $41.0 \%$ & 39 & 100 & $\begin{array}{c}.04 \\
0\end{array}$ & $\begin{array}{c}3,08 \\
0\end{array}$ \\
\hline Kurang & 7 & $\begin{array}{c}\% \\
31.8 \\
\%\end{array}$ & 15 & $68.2 \%$ & 22 & 100 & & \\
\hline $\begin{array}{l}\text { Pekerja } \\
\text { an } \\
\text { Bekerja }\end{array}$ & 17 & 73.9 & 6 & $26.1 \%$ & 23 & 100 & $\begin{array}{c}.00 \\
2\end{array}$ & $\begin{array}{c}5,44 \\
9\end{array}$ \\
\hline $\begin{array}{l}\text { Tidak } \\
\text { Bekerja }\end{array}$ & 13 & $\begin{array}{c}\% \\
34.2 \\
\%\end{array}$ & 25 & $65.8 \%$ & 38 & 100 & & \\
\hline $\begin{array}{l}\text { Motivasi } \\
\text { Tinggi }\end{array}$ & 26 & 63.4 & 15 & $36.6 \%$ & 41 & 100 & $\begin{array}{c}.00 \\
1\end{array}$ & $\begin{array}{c}6,93 \\
3\end{array}$ \\
\hline Rendah & 4 & $\begin{array}{c}\% \\
20.0 \\
\% \\
\end{array}$ & 16 & $20.0 \%$ & 20 & 100 & & \\
\hline
\end{tabular}

C. Analisis Multivariat

Hasil Seleksi Bivariat Untuk

Kandidat Multivariat $(p<0,25)$

\begin{tabular}{cccc}
\hline No & Variabel & $P$ Value & OR \\
\hline 1 & Umur & 0.052 & 1.385 \\
2 & Pendidikan & 0.023 & 3.750 \\
3 & Paritas & 0.055 & 2.769 \\
4 & Pengetahuan & 0.045 & 3.080 \\
5 & Pekerjaan & 0.004 & 5.449 \\
6 & Motivasi & 0.003 & 6.933 \\
\hline
\end{tabular}

D. Pemodelan Multivariat

Setelah dilakukan pemodelan kedua, selanjutnya dilihat perubahan nilaiOR (OR sebelum variabel $X$ dikeluarkan - OR setelah variabel $\mathrm{X}$ dikeluarkan /OR sebelum variabel $\mathrm{X}$ $\begin{array}{lllll}\text { dikeluarkan } & \text { x } & 100 & \% \text { ) pada }\end{array}$ variabel independen yang lainnya dengan atau tanpa variabel pengetahuan adalah pada tabel sebagaiberikut :

\begin{tabular}{llllrl}
\hline No & Variabel & $\begin{array}{l}P \\
\text { Value }\end{array}$ & OR & 95\% & \\
& & & CI & \\
\hline & & & & Lower & Upper \\
\hline 1 & Motivasi & 0.003 & 6.933 & 1.954 & 24.605 \\
\hline
\end{tabular}

\section{Pembahasan}

\section{Umur}

Pada usia 31-40 tahun merupakan usiadewasa, dalam hal berpikir seseorang lebihlogis, sehingga daya ingat dan cara pandanglebih luas terhadap informasi sehingga mudahmengingat dan memahami suatu hal yangbaru. Dengan dengan bertambahnya umurmaka akan menjadikan ibu semakin dewasadalam hal berpikir untuk memenuhikebutuhan dirinya. [2]

Kematangan usia seseorangmempengaruhi proses pengambilankeputusan dan proses berfikir dalammelakukan suatu kegiatan. Semakincukup umur, tingkat kematangan dankekuatan seseorang akan lebih matangdalam 
berfikir. Hasil analisis bivariat dengan menggunakan uji chi square diperolehn ilai $p<$ 0,05yang artinya ada hubungan tingkat pengetahuan ibu hamil dengan keikutsertaanibuhamil dalam melakukan senam hamil[11]

\section{Pendidikan}

Hasil analisis bivariat dengan menggunakan uji chi square diperoleh nilai $p=$ 0,745 yang artinya ada hubungan tingkat pendidikan ibu hamil dengan keikutsertaan ibuhamil dalam melakukan senam hamil. [6]

Tingkat pendidikan juga mempengaruhi sejauh mana ibu hamil tahu dan memahami tentang senamhamil Dimana senamhamil adalah suatu terapi latihan gerakuntuk mempersiapkan ibu hamil baiksecara fisik dan mental pada persalinancepat, aman dan spontan. Hal ini menunjukkan bahwasemakin tinggi pendidikan ibu hamilmaka ibu hamil semakin aktifmelakukan senam hamil.Denganpendidikan menengah ibu hamilmemiliki pemahaman dan wawasanyang luas tentang manfaat dari senam hamil.

Pengetahuan yang didapat kurang danjuga kurangnya minat atau keinginandari sang ibu hamil membuatnya jugatakut untuk mengikuti senam hamil.Selain itu walaupun seorang ibu hamilberpendidikan tinggi ada juga seorangibu yang tidak mengikuti senam hamil.

\section{Paritas}

Sebagian besar ibu primipara dan sebagian kecil ibu nullipara pada responden yang mengikuti senam hamil. Paritas adalah banyaknya kelahiran hidup yang dipunyai oleh seorang wanita. [8]
Senam hamil jarang diikuti ibunullipara bisa dikarenakan kurangnyainformasi tentang manfaat senam hamil untukmenghadapi persalinan. Sedangkan bagi ibuprimipara selain informasi yang kurang bisajuga karena kesibukan pekerjaan sehinggamenyita waktu untuk melakukan senam hamil.Banyaknya pengalaman dalam persalinan jugamenentukan besarnya partisipasi ibu dalammengikuti senam hamil. [1]

\section{Pengetahuan}

Berdasarkan hasil (pvalue $=$ $0,0116<$ $0,05)$ dapat dinyatakanHasil analisis bivariat dengan menggunakan uji chi square diperoleh nilai $p=$ 0,005yang artinya ada hubungan tingkat pengetahuan ibu hamil dengan keikutsertaan ibuhamil dalam melakukan senam hamil.

Hasil penelitian ini sesuai dengan teori yang dikembangkan oleh Green, bahwapengetahuan merupakan faktor predisposisi yang menentukan perilaku seseorang.Pengetahuan merupakan hasil tahu dan ini terjadi setelah seseorang melakukanpengindraan terhadap obyek tertentu. Sebagian besar pengetahuan manusia diperolehmelalui indra mata, telinga. Pengetahuan atau kognitif merupakan domain yang sangatpenting untuk terbentuknya tindakan seseorang/overt behavior. Perilaku yang didasarioleh pengetahuan akan lebih bermakna daripada perilaku yang tidak didasaripengetahuan. Perilaku yang dimaksud dalam penelitian ini adalahkeikutsertaan ibu hamil dalam melakukan senam hamil [9]

Dalam perkembangannya, masihbanyak ibu hamil yang jarang melakukansenam hamil 
diantaranya karena

kurangnyapengetahuan ibu terhadap senam hamil dantidak aktifnya pelaksanaan senam hamil,sehingga berdampak negatif terhadap keadaanibu dan janinnya. Dampak ibu yang tidakmelakukan senam hamil lebih rentanmengalami ketegangan jiwa dan fisik yangmenyebabkan persendian dan otot kaku,sehingga akan mengakibatkan memperlambatproses persalinan

Seseorang yang mempunyai pendidikan lebih tinggi akan lebih mudah

$\begin{array}{lrr}\text { menerima } & \text { informasi yang } \\ \text { disampaikan oleh } & \text { tenaga } \\ \text { kesehatan. Artinya, ra } & \text { ianan } \\ \text { dapatmengadopsi inovasi } & \text { dengan } \\ \text { cepat dibandingkan dengan ibu-ibu } \\ \text { berlatarbelakangpendidikan rendah } \\ \text { yang cenderung sulit untuk } \\ \text { mengetahui atau mengikuti } \\ \text { informasiyang tersedia dengan } \\ \text { keterbatasan pengetahuan.[10] }\end{array}$

\section{Pekerjaan}

Kesibukan bekerjamembuat ibu hamil yang berpendidikantinggi tidak dapat mengikuti senamhamil. Ibu hamil yang bekerja pastinyaakan sedikit kerepotan membagi waktuantara bekerja dengan mengikuti senamhamil. Jadi jelas bahwa ada hubunganantara tingkat pendidikan ibu hamildengan keikutsertaan senam hamil.

bekerja bagi ibu ibu akan mempunyai pengaruh terhadap kehidupannya sehingga ibu tidak punya banyakwaktu untuk mendapatkan informasi. Manusia memerlukan suatu pekerjaan untuk dapatberkembang dan berubah. Seseorang bekerja bertujuan untuk mencapai suatu keadaanyang lebih daripada keadaan sebelumnya.
Dengan bekerja seseorang dapat berbuat yangbernilai, bermanfaat dan memperoleh berbagai pengalaman.[11]

Beberapa faktor yang dapat mempengaruhi keikutsertaan ibu hamil dalam senam hamil meliputi: yaitu pekerjaan, paritas.sebagian besar ibu hamil bekerja swasta dan sebagian kecil sebagai buruh tani. Ibu hamil yang bekerja cenderung menghabiskan sebagian besar waktunya untuk bekerja sehingga partisipasi dalam mengikuti senam hamil pun jarang bahkan sampai tidak pernah ikut. Ibu hamil yang bekerja juga ada yang merasa lelah dan capek setelah bekerja sehingga lebih memilih[3]

\section{Motivasi}

\section{Hasil}

uji chisquaremenunjukkan bahwa nilai $\mathrm{p}$ $=0.002(\mathrm{p}=<0,05)$ yang menunjukkan bahwa adahubungan motivasi dengankeikutsertaan ibu hamil mengikutisenam. Penelitian ini didukungdengan penelitian Haswita (2012)menunjukkan bahwa ada hubunganantara motivasi ibu hamil denganpelaksanaan senam hamil dengan nilaip $=0,001$.

Motivasi ibu hamil dengan pelaksanaansenam hamil memiliki hubungan yangsangat erat. Dimana seseorang yangtelah termotivasi untuk melakukansesuatu, maka akan berusaha melakukansesuatu tersebut dengan baik dan tekun,dengan harapan hasil yang baik. Motivasi seseorang yang disebabkanoleh kemauan sendiri bukan daridorongan luar akan lebihmenguntungkan [8] 


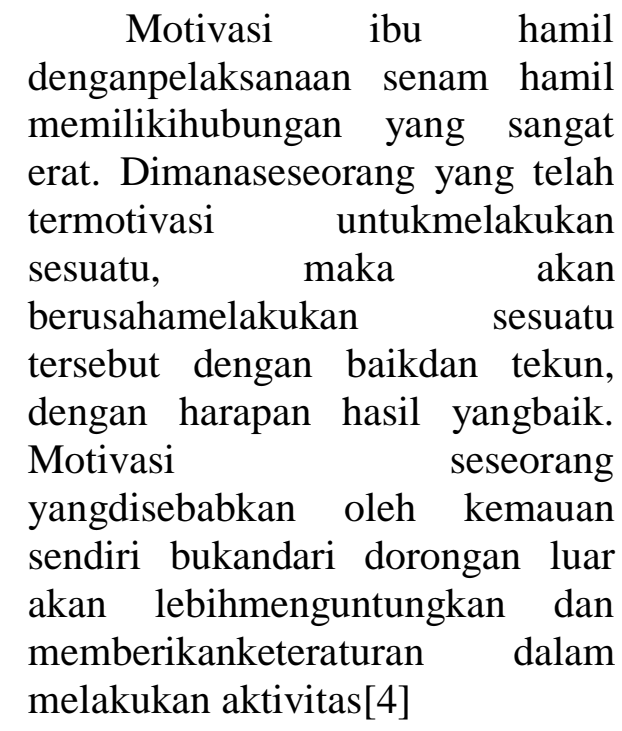

SIMPULAN

Ada pengaruh secara signifikan antara pengetahuan, pekerjaan, motivasi, pendidkani terhadap keikutsertaan dalam senam hamil di Rumah Bersalin Dince Safrina, SST dan Motivasi ibu hamil berpengaruh 6,9 kali terhadap pelaksanaan senam hamil. Motivasi yang tinggi baik dari keluarga, orang terdekat dan dari diri pribadi ibu hamil tersebut sangat berpengaruh terhadap pelaksanaan senam hamil.

\section{SARAN}

1. Bagi Instansi Pelayanan Hasil penelitian ini diharapkan dapat menjadi informasi tambahan dalam pengembangan pendidikan kebidanan tentang senam hamil.

2. Bagi Ibu hamil supaya dapat melakukan senam hamil secara rutin sehingga dapat menurunkan kecemasan menghadapi persalinan dan memperlancar persalinan.
[1] Wahyuni \& Nida. Q, "Pengaruh Senam Hamil Terhadap Perubahan Kadar Hemoglobin (Hb) Pada Kehamilan Trimester Ketiga," Ju-rnal Kesehat., vol. 3(2), 2010.

[2] Wulandari P. Y, "Efektivitas Senam Hamil Seba-gai Pelayanan Prenatal Dalam Menurunkan Kecemasan Menghadapi Persalinan Pertama," INSAV, vol. 8(2): 144, 2006.

[3] A. Sulistiyawati, Asuhan kebidanan pada masa kehamilan. Jakarta: Salemba Medika, 2009.

[4] R. A. Pudiastuti, Buku Ajar ;

Kebidanan Komunitas. Yogyakarta: Haikhi, 2011.

[5] S. Bandiyah, Kehamilan ,persalinan, dan gangguan kehamilan. Yogyakarta: Nuha Medika, 2009.

[6] M. Indriatai, Senam Hamil dan Balita. Yogyakarta: Cemerlang publishing, 2008

[7] G. . Mandriati, Panduan Belajar Asuhan Kebidanan Ibu Hamil. Jakarta: EGC, 2008.

[8] A. B. Nirwana, Kapita Selekta Kehamilan. Yogyakarta: Nuha Medika, 2011.

[9] S. Notoatmodjo, Metodologi Penelitian Kesehatan. Jakarta: Rineka Cipta, 2010.

[10] Wawan, A dan Dewi, M.. Teori dan Pengukuran Pengetahuan, Sikap, dan Perilaku Manusia. Nuha Medika, Yogyakarta, 2010 [11]Widianti. 2013. Senam Kesehatan Dilengkapi dengan Contoh Gambar. Yogyakarta : Nuha Medika

\section{DAFTAR PUSTAKA}

